\title{
Easier Left Sided Bronchial Blocker Placement Using Middle Fixation of Endotracheal Tube and Real Time Wireless Video Fiberoptic Bronchoscopy
}

\author{
Hou Chuan Lai, Yi Chin Lin and Zhi Fu Wu* \\ Department of Anesthesiology, Tri-Service General Hospital and National Defense Medical Center, Taipei, Taiwan, Republic of China
}

Received: 眥 January 19, 2019; Published: 制January 24, 2019

*Corresponding author: Zhi Fu Wu, Department of Anesthesiology, Tri-Service General Hospital and National Defense Medical Center, Taipei, Taiwan, Republic of China

Abbreviations: BB: Bronchial Blocker; FOB: Flexible Fiberoptic Bronchoscope; ETT: Endotracheal Tube

\section{Editorial}

In our institute, Dr. Cherng's article: "Middle fixation of electromyographic endotracheal tube for intraoperative recurrent laryngeal nerve monitoring" [1], they described that electromyographic endotracheal tube (ETT) should be affixed at the middle of the mouth to avoid missing contact with one side vocal cord. However, we'd like to share our experience of using middle fixation of the EET and real-time wireless video fiberoptic bronchoscopy for facilitating left-sided bronchial blocker (BB) placement. BB products typically have been deployed within the ETT or intraluminally after intubation for one lung ventilation [2]. However, intraluminal placement of these devices sometimes can be challenging, with both the blocker and flexible fiberoptic bronchoscope (FOB) present within the ETT, especially the leftsided BB placement $[3,4]$.

Moreover, the angle of tracheobronchial relationship favored the preferential passage of the right-side BB placement [4]. Therefore, in order to increase the success rate of left-sided BB placement, the extraluminal placement technique and using the preshaped Fogarty catheter as a bronchial blocker have been developed $[4,5]$. But the extraluminal placement technique is prone to sorethroat or hoarseness, and the success rate of preshaped Fogarty catheter to the left bronchus is low $(18.2 \% ; 2 / 11)[3,4]$. Here, we introduce a new method to make left-sided BB placement easier by using middle fixation of EET and real-time wireless video fiberoptic bronchoscopy. After tracheal intubation with a EET (I.D. $7.0 \mathrm{~mm}$ for women and $7.5 \mathrm{~mm}$ for men), we kept the EET affixed between incisors, at the middle of the mouth (Figure 1) and the distal ETT within $2-5 \mathrm{~cm}$ above the carina to improve the visual field , because tube rotation and deviation may occur when the ETT is affixed at the right or left mouth corner [1,6]. Then, a BB (Coopdech endobronchial blocker tube, Daiken Medical Corp., Osaka, Japan) was advanced through the blocker port of its special multiport connector and the $2.8 \mathrm{~mm}$ FKScope (WD-OD28-160K-47-A1, Johnfk Medical Inc., New Taipei City, Taiwan), a real-time wireless video fiberoptic bronchoscopy, that had been introduced through the fibreoptic port. And the blocker is advanced with a counterclock twisting motion to direct it into the left main bronchus under the FKScope . Finally, the blue balloon of the BB was inflated and the correct position was confirmed with the FKScope (Figure 2) and auscultation.

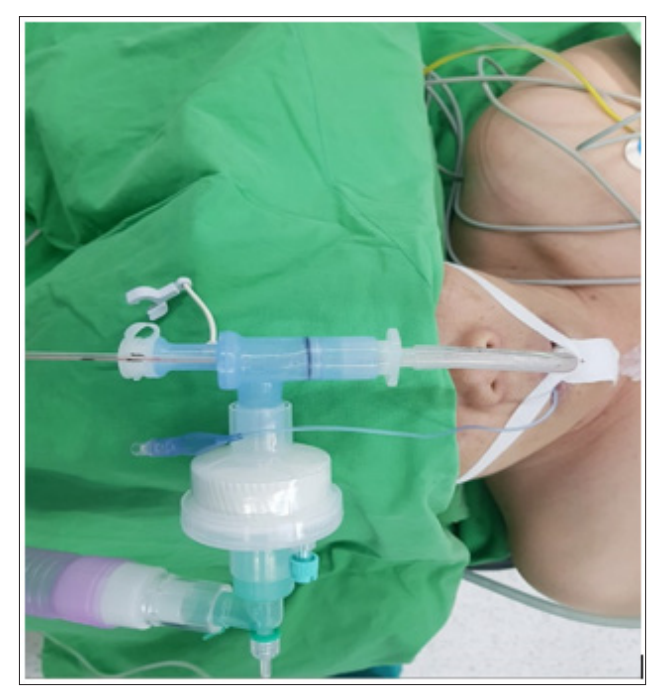

Figure 1: The endotracheal tube is affixed between incisors, at the middle of the mouth. 


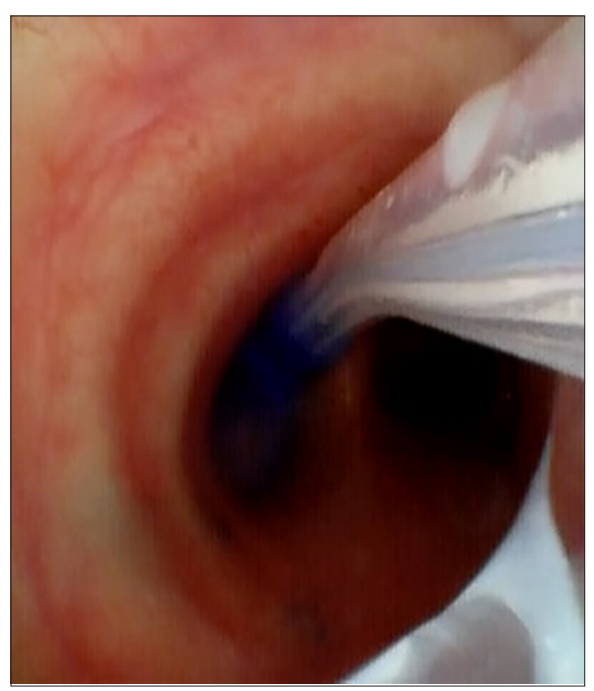

Figure 2: Place the bronchial blocker into the left main bronchus by using wireless video fiberoptic bronchoscopy.

ISSN: 2574-1241

DOI: $10.26717 / B J S T R .2019 .13 .002415$

Zhi Fu Wu. Biomed J Sci \& Tech Res

This work is licensed under Creative Commons Attribution 4.0 License

Submission Link: https://biomedres.us/submit-manuscript.php

\section{References}

1. Cherng CH, Huang YH, Shih ML (2014) Middle fixation of electromyographic endotracheal tube for intraoperative recurrent laryngeal nerve monitoring. J Clin Anesth 26(3): 252-253.

2. Narayanaswamy M, Mc Rae K, Slinger P, Dugas G, Kanellakos GW, et al. (2009) Choosing a lung isolation device for thoracic surgery: A randomized trial of three bronchial blockers versus double-lumen tubes. Anesth Analg 108(4):1097-1101.

3. Templeton TW, Morris BN, Goenaga Diaz EJ, Forest DJ, Hadley R, et al. (2017) A Prospective Comparison of Intraluminal and Extraluminal Placement of the 9-French Arndt Bronchial Blocker in Adult Thoracic Surgery Patients. J Cardiothorac Vasc Anesth 31(4): 1335-1340.

4. Chengod S, Chandrasekharan AP, Manoj P (2005) Selective left bronchial intubation and left-lung isolation in infants and toddlers: analysis of a new technique. J Cardiothorac Vasc Anesth 19(5): 636-641.

5. Stephenson LL, Seefelder C (2011) Routine extraluminal use of the 5F Arndt endobronchial blocker for one-lung ventilation in children up to 24 months of age. J Cardiothorac Vasc Anesth 25(4): 683-686.

6. Cohen A, Tan L, Fargo R, Anholm JD, Gasho C, et al. (2018) A multi-center evaluation of a disposable catheter to aid in correct positioning of the endotracheal tube after intubation in critically ill patients. J Crit Care 48: 222-227.

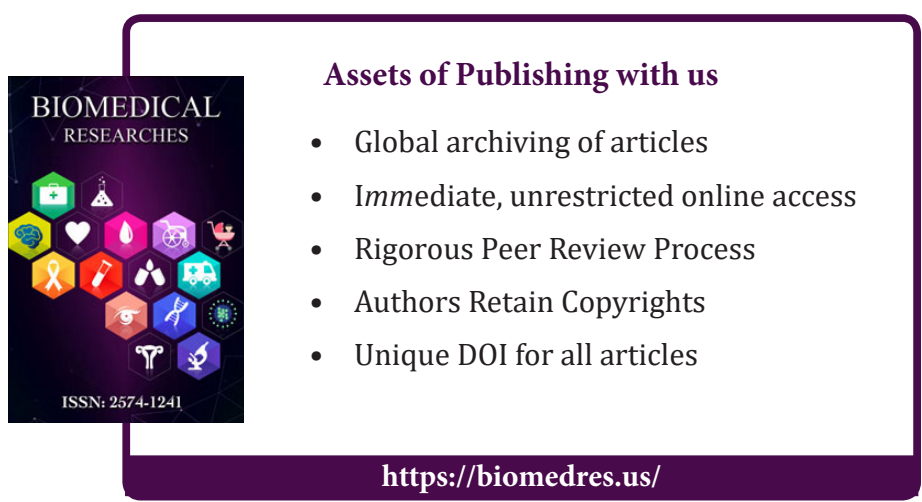

